mutual responsibility, as the squalor of the patients' kitchen and the thefts from the laundry room served to demonstrate. From the staff side, there was a fine line to be drawn between encouraging patients to support themselves and letting them interfere with each other's management.

Ward atmosphere obviously changed according to the activities of its most vociferous patients, but it was at its most depressing whenever the doors were locked during the day. This measure was only used when absolutely necessary, but it always had an effect on morale and increased the sense of stigmatisation already felt by many. Ward routine was very important for many patients, particularly those who had improved sufficiently to take an interest in the programme offered, but at the same time they could be very unflexible and intolerant of change or interruption. An important aspect of ward policy in encouraging reintegration into normal living when the time came was therefore the flexible and tolerant approach to visiting hours and leave arrangements.

\section{Acknowledgements}

I would like to thank the medical and nursing staff who helped me through what could have been a nightmare. My thanks are due particularly to Jo, Tony and David for their care and help, and to Charlie, Ivana, Andrew, Jo, Richard, Lesley, Helen and Shelagh for their unstinting support.

\title{
Multi-centred day units in a psychiatric rehabilitation service
}

\author{
N. Rothwell, Principal Clinical Psychologist; A. A. McKeChNIE, Consultant \\ Psychiatrist*; and D. LoRIMER, Research Assistant, Bangour Village Hospital, \\ Broxburn, West Lothian EH52 6LW \\ *now HM Medical Commissioner, Mental Welfare Commission for Scotland, \\ 25 Drumsheugh Gardens, Edinburgh EH3 7RB
}

Psychiatric day care has expanded considerably over the past 20 years. Day hospitals may serve as alternatives to short-stay in-patient units or speed discharge from them. Day services are also necessary to ensure appropriate support for patients with chronic disability, especially chronic functional psychosis, if they are to remain in a community setting (these are often called day hospitals to ensure NHS support). The present paper focuses on this latter group and describes the characteristics of day attenders in a service that has developed a multi-facility approach to community support.

Bangour Village Hospital provides a comprehensive service to a population of approximately 140,000 . It has a day hospital specifically identified as a rehabilitation and long-term support facility which provides 40 places on a 5 -day week basis with major emphasis on work placement or participation in an occupational therapy programme. Associated with the day hospital are two community clubs run on a sessional basis by day hospital staff. One unit, the Whitburn ' $81 \mathrm{Club}$, is based in a community centre and provides facilities within this with support principally from NHS staff. The second facility is based in a community school in Livingston New Town and activities are conducted there on a sessional basis using NHS and community education staff. A community school provides vocational and non-vocational educational facilities for children and adults. It is open six days a week for most of the year for up to 14 hours a day.

Depot neuroleptic clinics are also held in various locations within the catchment area. 


\section{Aims of survey}

(a) To identify the social and demographic characteristics of all attenders at related day units:

(i) Bangour Village Hospital (Base)

(ii) Community centre (Whitburn)

(iii) Community school (Livingston)

(iv) Depot neuroleptic clinics.

(b) To examine whether the four day units differ in terms of the characteristics of the attenders.

(c) To conduct a consumer survey of attenders. This was to investigate the feasibility and potential usefulness of systematically obtaining consumer feedback and is described in detail elsewhere (Rothwell et al, 1989).

\section{The study}

A research worker (Ms DL) obtained information relating to age, sex, ICD Classification of Mental Illness, duration and type of previous psychiatric contact if known, duration and type of current day hospital contact as well as other relevant demographic information. A Morningside Rehabilitation Status Scale (MRSS) was completed by nursing and occupational therapy staff for each patient (Affleck \& Maguire, 1984).

This scale identifies four inter-related factors: dependence-independence; isolation-integrated; inactivity-activity; and effects of current symptoms. The resulting total score divides into three levels of functioning - mild (0-8) moderate (9-16) and severe (17-28) impairment.

A census was conducted during October 1987 and the information obtained formed the basis of a period prevalence survey. In addition all subjects were asked to complete the consumer survey form in which they were asked to rate their own satisfaction with regard to identified services, staff contact, medication, work placement etc.

All data recorded were computerised and tabulated, the results analysed using EMAS computing service and comparisons made between differing populations using standardised techniques, e.g. t-tests.

\section{Findings}

Information was gathered on subjects attending four services (Table I).

Eighty-four men and 62 women formed the survey group, 146 in all. Forty-seven attended the hospital based day facilities and a similar number attended depot neuroleptic clinics alone. Men predominated in the community clubs - but more women attended for neuroleptics alone. The mean age was 46 (s.d. = 13) the range being $21-76$ years. Those attending Deans Community School were younger than other
TABLE I

Distribution of subject across four community facilities (percentages in brackets)

\begin{tabular}{lccc}
\hline & Male & Female & Total \\
\hline Bangour Village Hospital & $30(64)$ & $17(36)$ & 47 \\
Deans Community Club & $17(55)$ & $14(45)$ & 31 \\
Whitburn '81 Club & $16(76)$ & $5(24)$ & 21 \\
Injection Clinics & $21(45)$ & $26(55)$ & 47 \\
\hline Total & $84(57)$ & $62(43)$ & 146 \\
\hline
\end{tabular}

attenders with a mean age of 37 (s.d. $=11$ ), range 2160 . Twenty-eight per cent lived alone and $53 \%$ of all attenders were single. A higher proportion of single people attended the base (BVH) day hospital and also Deans Community Club but no other differences emerged between any of those attending the four units.

The principal diagnosis using ICD classifications was ascertained (Table II). Schizophrenia was the commonest diagnosis and $70 \%$ of all attenders had been diagnosed as suffering from functional psychosis. As might be expected, there were diagnostic differences between the users in each facility. While schizophrenia remained the single most common diagnosis among day attenders, only about a half were so diagnosed.

The number of previous admission episodes including those as day patients was analysed. Overall the mean was 5.1 admissions $(s . d .=4)$, the range being 0-29.

The mean length of current attendance was two years (s.d. of 18 months). The length of attendance was up to eight years but comparisons between facilities were not possible as each facility had been in existence for a variable period of time. The day hospital subjects who had been attending for at least one year represented a rate of 57 per 100,000 total population at risk.

Using the MRSS, $56 \%$ were rated as mild, $39 \%$ as moderate and $5 \%$ - seven subjects living at homewere severely disabled. Of the seven people who were severely disabled, six had a diagnosis of schizophrenia and one of organic psychosis. They were four men and three women with an age range of 26-58 (mean age 40). Three attended injection clinics only, while the others attended other units though not the Deans Community Club. As a whole, those attending Deans Club were the least disabled. No significant differences in functioning were apparent in the other groups of day attenders.

\section{Comment}

Viewed very simplistically, the day hospitals and the depot neuroleptic clinic identified in West Lothian 
TABLE II

Principal diagnosis using ICD classification (percentages in brackets)

\begin{tabular}{|c|c|c|c|c|c|c|c|}
\hline & Schizophrenia & $\begin{array}{c}\text { Manic } \\
\text { depressive } \\
\text { psychosis }\end{array}$ & Neurosis & $\begin{array}{c}\text { Personality } \\
\text { disorder }\end{array}$ & Alcoholism & $\begin{array}{c}\text { Organic } \\
\text { psychosis }\end{array}$ & Other \\
\hline $\begin{array}{l}\text { Bangour Village Hospital } \\
\text { Deans Community Club } \\
\text { Whitburn ' } 81 \text { Club } \\
\text { Injection Clinics }\end{array}$ & $\begin{array}{r}24(53) \\
9(43) \\
8(38) \\
41(89)\end{array}$ & $\begin{array}{l}7(16) \\
3(14) \\
1(5) \\
0\end{array}$ & $\begin{array}{l}0 \\
1(5) \\
5(24) \\
0\end{array}$ & $\begin{array}{l}7(16) \\
2(9) \\
2(9.5) \\
0\end{array}$ & $\begin{array}{l}0 \\
0 \\
3(14) \\
2(4)\end{array}$ & $\begin{array}{l}4(9) \\
1(5) \\
2(9.5) \\
0\end{array}$ & $\begin{array}{l}3(6) \\
5(24) \\
0 \\
3(7)\end{array}$ \\
\hline Total & $82(62)$ & $11(8)$ & $6(5)$ & $11(8)$ & $5(4)$ & $7(5)$ & $11(8)$ \\
\hline
\end{tabular}

provide support for nearly 150 subjects or five fully staffed wards. Although schizophrenia was the single most common diagnosis almost half of those attending had other diagnoses, including organic brain syndrome, alcohol related problems and personality disorders.

The MRSS was devised to identify in-patients suitable for a rehabilitation programme as well as those placed in the community. Seven of the subjects were severely disabled, all lived with relatives and in an objective assessment of in-patients would not have been considered potential rehabilitation prospects. They indicate the support, usually ignored, provided by many families. Of the others, almost half were moderately disabled. Numbers were too small within individual groups to allow statistical comparison by each variable. Overall those attending Deans Community School were the least disabled. The MRSS is a useful device to identify current state and also to review progress. A subsequent review of attenders demonstrated that staff with predominantly hospital-based experience tended to under rate on the dependency sub-scale. This point needs to be borne in mind in the training of staff utilising this measurement. The effect is to over estimate the level of functioning in the population surveyed.

The day hospital attenders represent a rate of 57 per 100,000 total population at risk who had attended for at least one year. A survey of day hospital facilities in the City of Edinburgh (Philip \& Stuckey, 1988) showed a comparable figure and also showed that the majority of those with functional illness requiring long-term care were resident in the community - not in long-stay in-patient beds. Thus community care is well developed in some parts of Scotland although in others there continues to be a high utilisation of in-patient beds (McCreadie et al, 1985).

Two of the facilities identified have been grafted on to existing facilities - a community centre and a community school (Macaulay, 1989). They appear to present acceptable alternatives to NHS-owned facilities but do require enthusiastic joint support from all agencies involved.
The characteristics of those attending three of the four facilities, the day hospital, the community centre and the depot injection clinic do not differ substantially, except that a diagnosis of schizophrenia predominated in those attending only the injection clinics. The value of these units lies more in the different type of support they offer. The Whitburn ' 81 Club allows a generic community facility to be utilised in a location some seven miles from the base hospital, while the injection clinic, besides its specific main function, provides continuing support through out-patient attendance and home visits alone. The community school attenders are a distinct sub-group in that they are younger and less disabled.

Rothwell et al (1989) looked specifically at what consumers valued about their attendance at these day facilities. Consumers rated vocational activity, help with fares and the provision of free meals as most important, highlighting the financial difficulties associated with multiple disability and high dependency needs. These have to be very carefully monitored by all involved in care and aftercare in the community. Attenders require long-term support. Such support is necessary to prevent deterioration and is clearly a very important aspect of rehabilitation.

\section{References}

Affleck, J. W. \& Maguire, R. J. (1984) Measurement of psychiatric rehabilitation status. British Journal of Psychiatry, 145, 517-525.

Macaulay, R. (1989) Back to school. Nursing Times, 85, 3537.

McCreadie, R. G., Affleck, J. W. \& Robinson, A. D. (1985) The Scottish survey of psychiatric rehabilitation and support services. British Journal of Psychiatry, 147, 289-294.

Philip, A. E. \& StuckeY, N. (1988) Service provision for long-term non-resident psychiatric patients. Health Bulletin, 46, 311-317.

ROTHWELL, N., LORIMER, D. \& MCKeCHNIE, A. A. (1989) A consumer survey of two psychiatric day hospitals. International Journal of Health Care, 2, 17-21. 